\title{
Neuroanatomical Basis of Glasgow Coma Scale-A Reappraisal
}

\author{
Sunil Munakomi, Bijoy Mohan Kumar \\ Department of Neurosurgery, College of Medical Sciences, Chitwan, Nepal \\ Email: Sunilmunakomi@gmail.com
}

Received 18 July 2015; accepted 5 September 2015; published 8 September 2015

Copyright (C) 2015 by authors and Scientific Research Publishing Inc.

This work is licensed under the Creative Commons Attribution International License (CC BY). http://creativecommons.org/licenses/by/4.0/

c) (i) Open Access

\begin{abstract}
Glasgow coma scale is the most cited paper in neurosurgery. It has vast implications in the fields of neurology and neurosurgery. But lack of proper understanding in the neuro-anatomical basis of the score is the Achilles heel in proper utilization of the same. Herein we review the anatomical aspects behind each variable in the score. We also discuss common limitations of the score and highlight future directives to limit the same.
\end{abstract}

\section{Keywords}

Glasgow Coma Scale, Anatomy

\section{Introduction}

Glasgow coma scale was postulated by Jennet and Teasdale in 1974 as a practical method for bedside assessment of impairment of conscious level, the clinical hallmark of acute brain injury [1]. The aim is to categorize the patients with traumatic head injury into mild, moderate and severe head injury. Originally it had total score of 14 but later, further categorization of normal and abnormal flexion (withdrawal and decorticate) led to revised total score of 15 points [2]. This has stood the test of time for over 40 years now. GCS score also has predictive value on the prognosis and the outcome of the patient.

GCS emphasizes how brain integrates, comprehends and analyzes different functional aspects by incorporating three independent variables in the score system [3].

It is therefore prudent for reappraisal on the neurology behind the GCS score.

\section{Anatomical Foundation behind Glasgow Coma Scale}

This can be divided into cortical, sub-corticol, brainstem and cervico-medullary junction for simplicity. This is detailed in Table 1 (anatomy behind eye opening score), Table 2 (anatomy behind motor score) and Table 3 
Table 1. Neuroanatomy behind the eye opening score.

\begin{tabular}{cll}
\hline & \multicolumn{2}{c}{ Anatomical level for eye opening } \\
\cline { 2 - 3 } Eye opening & \multicolumn{1}{c}{ Clinical parameter } & Anatomical level \\
\hline 4 & Spontaneous & Corticol \\
3 & Command & Subcorticol (only goal directed saccades present) \\
2 & Pain & Lateral geniculate body \\
1 & Absent & Superior colliculus \\
\hline
\end{tabular}

Table 2. Neuroanatomical basis of motor score.

\begin{tabular}{cll}
\hline & & \multicolumn{1}{c}{ Anatomical level for motor opening } \\
\cline { 2 - 3 } Motor score & \multicolumn{1}{c}{ Clinical parameter } & Anatomical level \\
\hline 6 & Obeys command & Corticol \\
5 & Localise pain & Above basal ganglion \\
4 & Withdrawal from pain & Basal ganglion \\
3 & Flexion & Below red nucleus \\
2 & Extension & Below vestibular nucleus \\
1 & Absent & Cervico-medullary region \\
\hline
\end{tabular}

Table 3. Neuroanatomy behind the verbal response.

\begin{tabular}{ccc}
\hline Verbal response & & Anatomical level for verbal response \\
\cline { 2 - 3 } & Clinical parameter & Anatomical level \\
4 & Oriented & Corticol \\
3 & Disoriented & Inappropiate \\
2 & Incomprehensible & Subcorticol and deep nuclear region \\
1 & Absent & Auditory fasciculus \\
area in left temporal lobe & Inferior colliculus \\
\hline
\end{tabular}

(anatomy behind verbal score).

This knowledge helps us to pinpoint the probable site of injury to the brain. Also one of the limitations of the score being its skewedness towards the motor score can be detailed to the fact that most of the patients with TBI have raccoon eyes and peri-orbital swelling that may hinder in proper assessment of eye opening. Similarly, assessment of verbal score in patients who are sedated paralyzed or on tracheotomy can be problematic. In them, motor score provides rough estimation of the prognosis. Similarly, inter-rater bias can be minimized by understanding the fact that all individual scores should roughly estimate towards similar location of injury and thereby should not vary by more than 2 points.

\section{Eye Opening}

Whenever we are confronted to threats in our natural environment, we link our visual processing mapping to its associated motor behavior to terminate the exposure to an aversive event [4].

In normal scenario, we take clues of other sensory stimuli like vision to aid in our escape phenomenon by taking a correct timely decision. Visual stimuli provides clue about the impending danger to Superior Colliculus. It then orients us to the scenario [5].

Then comes the role of basal ganglion. Basal ganglia are involved in the Fixed Action Patterns (FAPs) of muscular movements of spoken language [6]. It has the function of "action selecting"-that is, to implicitly weigh all available options and choose the best one. In addition to the response selection function by competition, the basal ganglia may enable signals originating from non-motor parts of the cerebral cortex to be mapped onto motor signals to produce behavioral output. The internal cueing mechanism between basal ganglia and supplementary motor area controls the timing of submovement initiation. Putamen engages in cortical initiation while the cerebellum amplifies and refines this signal to facilitate correct decision making [7].

The pulvinar contains neurons that generate signals related to the salience of visual objects. It plays a role in 
observation, suppression and distraction of irrelevant stimuli, augment response and finally modulating the behavioral attention [8].

Lastly the role of pain in the defense mechanism. Studies have shown that VPL precisely encode the intensity of noxious stimuli [9]. The ventromedial nociceptive neurons involves in the attentional reactions and/or the coordination of motor responses to pain [10] such as eye opening to pain.

Lastly absence of eye opening to any stimulus relates to the anatomical region surrounding the peri-aqueductal gray. The area ventral to the peri-aqueductal grey matter is related to eyelid closure, while the area dorsal to the peri-aqueductal grey matter is related to eye opening [11].

\section{Motor Score}

Along with the course of evolution, we have acquired the ability to maintain the adaptive postures and to move the body parts in a coordinated fashion [12] [13].

Four major achievements of somatomotor evolution have been represented in Table 4 in the order of their development.

The evolution of the central pattern generators has made it possible to coordinate the rhythmic movement activity despite minimal input from the higher control centre just by the process of disinhibition [14].

Phylogenetically, the extra pyramidal tracts developed earlier from the reticular formation cells and nuclei as compared to pyramidal tracts developing from the pyramidal cells later on.

The rubrospinal tract helps to flex the upper limb so any lesion above it, the flexor attitude seen in decorticate posturing is observed. On the contrary vestibulospinal tract extends both the upper and the lower extremities with the influence on antigravity muscles thereby bringing the decerebrate posturing [15].

Lesion below the vestibular nucleus leads to flaccid paralysis of all the extremities.

\section{Verbal Response}

To address the anatomy behind the scores of verbal response, we briefly discuss the neurology of hearing.

Speech codes first relay on inferior colliculus [16] (lesion here leads to incomprehensible speech).

Early stages of speech recognition are bilaterally (but not necessarily symmetrically) organized in the superior temporal lobe. Beyond that the speech processing stream diverges into two pathways, one supports comprehension, and another governs the aspects of speech production and phonological short-term memory [17].

Early auditory processing and word recognition take place in inferior temporal areas ("what" pathway). Lesion here leads to inappropriate verbal response.

It is believed that the common route to speech production is through verbal and phonological working memory using the same dorsal stream areas implicated in speech perception and phonological working memory.

From Wernicke's area, the signal is taken to Broca's area through the arcuate fasciculus. The lesion in this level leads to inappropriate verbal response.

Then comes the role of basal ganglion in speech production. Left basal ganglia play an important role in regulating arousal and speech initiation, in monitoring the semantic and lexical aspects of language, and in switching from one linguistic element to the following during language production [18].

Putamen engages in cortical initiation while the cerebellum amplifies and refines this signal to facilitate correct decision making [19].

Lesions here produce disoriented speech as there is lack of additional sensory clues to guide the arcuate fasciculus and the ganglion for oriented language behavior.

Table 4. Order of evolution of motor function.

\begin{tabular}{lcc}
\multicolumn{1}{c}{ Order of evolution } & Function & Motor response \\
1. Antigravity postures & Resist against gravity & $\begin{array}{c}\text { Primitive movements generated by central pattern } \\
\text { generators in brainstem and spinal cord }\end{array}$ \\
2. Programmed patterns & Feeding and locomotion & Withdrawal to pain \\
3. Extremity movement & Targeting and grabbing & Localize to pain \\
4. Skilled digit movements & Dexterity and manipulation & Obeys command \\
\hline
\end{tabular}


Then at the cortical level speech is produced and this is continuously being checked by other sensory clues and the subcorticol centers so as to produce the oriented verbal output .It has been shown that the stimulation of the motor system influences language processing in a category-specific manner, thereby proving an active role of cortical motor systems in word recognition [20].

\subsection{Limitations of the Score}

There are limitations of the GCS [21]. Foremost being the lack of inclusion of the papillary reaction and the brainstem reflexes. The GCS is widely perceived as complicated with chances of inter-rater reliability [22]. Another drawback is its limitation in those patients who are either sedated, under drug influences or are intubated [23]-[26]. To address the same issue, the modified GCS score has also been studied implicating only the motor score [27].

There are also other scoring system like Marshall and Rotterdam scores [28] and clinical score like the AVPU [29] and FOUR score system [30] but none have gained popularity and they also hold similar limitations.

\subsection{Future Directives}

1) Inclusions of CT scores to further validate the prognostic implication of the score system.

2) Application of post resuscitated GCS score to remove the confounding bias of hypoxia and hypotension.

3) Inclusion of trauma scores like revised trauma score to assess the confounding bias of associated polytrauma in traumatic head injuries.

\section{Conclusion}

The pivotal need is to remember the fact that GCS is not merely a numbering game, but it has sound anatomical basis. Understanding the same can be a clinical pearl to anyone concerned in roughly localizing the lesion. It may also help to reduce the inter-rater bias as there should be no difference in the individual component of the score by than 2 points, so as the anatomical basis dictates.

\section{References}

[1] Teasdale, G. and Jennett, B. (1974) Assessment of Coma and Impaired Consciousness. A Practical Scale. The Lancet, 2 , 81-84. http://dx.doi.org/10.1016/S0140-6736(74)91639-0

[2] Teasdale, G., Jennett, B., Murray, L. and Murray, G. (1983) Glasgow Coma Scale: To Sum or Not to Sum. The Lancet, 2, 678. http://dx.doi.org/10.1016/S0140-6736(83)92550-3

[3] McNett, M. (2007) A Review of the Predictive Ability of Glasgow Coma Scale Scores in Head-Injured Patients. Journal of Neuroscience Nursing, 39, 68-75. http://dx.doi.org/10.1097/01376517-200704000-00002

[4] Miskovic, V. and Keil, A. (2014) Escape from Harm: Linking Affective Vision and Motor Responses during Active Avoidance. Social Cognitive and Affective Neuroscience, 9, 1993-2000. http://dx.doi.org/10.1093/scan/nsu013

[5] Gandhi, N.J. and Katnani, H.A. (2011) Motor Functions of the Superior Colliculus. Annual Review of Neuroscience, 34, 205-231. http://dx.doi.org/10.1146/annurev-neuro-061010-113728

[6] Schall, J.D. (2001) Neural Basis of Deciding, Choosing and Acting. Nature Reviews Neuroscience, 2, 33-42. http://dx.doi.org/10.1038/35049054

[7] Booth, J.R., Wood, L., Lu, D., Houk, J.C. and Bitan, T. (2007) The Role of the Basal Ganglia and Cerebellum in Language Processing. Brain Research, 1133, 136-144. http://dx.doi.org/10.1016/j.brainres.2006.11.074

[8] Robinson, D.L. and Petersen, S.E. (1992) The Pulvinar and Visual Salience. Trends in Neurosciences, 15, $127-132$. http://dx.doi.org/10.1016/0166-2236(92)90354-B

[9] Peschanski, M., Guilbaud, G., Gautron, M. and Besson, J.M. (1980) Encoding of Noxious Heat Messages in Neurons of the Ventrobasal Thalamic Complex of the Rat. Brain Research, 197, 401-413. http://dx.doi.org/10.1016/0006-8993(80)91125-7

[10] Monconduit, L., Bourgeais, L., Bernard, J.F., Le Bars, D. and Villanueva, L. (1999) Ventromedial Thalamic Neurons Convey Nociceptive Signals from the Whole Body Surface to the Dorsolateral Neocortex. The Journal of Neuroscience, 19, 9063-9072.

[11] Esteban, A., Traba, A. and Prieto, J. (2004) Eyelid Movements in Health and Disease. The Supranuclear Impairment of the Palpebral Motility. Neurophysiologie Clinique, 34, 3-15. http://dx.doi.org/10.1016/j.neucli.2004.01.002 
[12] Kaas, J.H. (2008) The Evolution of the Complex Sensory and Motor Systems of the Human Brain. Brain Research Bulletin, 75, 384-390. http://dx.doi.org/10.1016/j.brainresbull.2007.10.009

[13] Mantini, D., Corbetta, M., Romani, G.L., Orban, G.A. and Vanduffel, W. (2013) Evolutionarily Novel Functional Networks in the Human Brain? The Journal of Neuroscience, 33, 3259-3275. http://dx.doi.org/10.1523/JNEUROSCI.4392-12.2013

[14] MacKay-Lyons, M. (2002) Central Pattern Generation of Locomotion: A Review of the Evidence. Physical Therapy, 82, 69-83.

[15] Bateman, D.E. (2001) Neurological Assessment of Coma. Journal of Neurology, Neurosurgery \& Psychiatry, 71, i13i17.

[16] Carlson, N.L., Ming, V.L. and DeWeese, M.R. (2012) Sparse Codes for Speech Predict Spectrotemporal Receptive Fields in the Inferior Colliculus. PLoS Computational Biology, 8, e1002594. http://dx.doi.org/10.1371/journal.pcbi.1002594

[17] Hickok, G. (2009) The Functional Neuroanatomy of Language. Physics of Life Reviews, 6, 121-143. http://dx.doi.org/10.1016/j.plrev.2009.06.001

[18] Fabbro, F., Clarici, A. and Bava, A. (1996) Effects of Left Basal Ganglia Lesions on Language Production. Perceptual and Motor Skills, 82, 1291-1298. http://dx.doi.org/10.2466/pms.1996.82.3c.1291

[19] Booth, J.R., Wood, L., Lu, D., Houk, J.C. and Bitan, T. (2007) The Role of the Basal Ganglia and Cerebellum in Language Processing. Brain Research, 1133, 136-144. http://dx.doi.org/10.1016/j.brainres.2006.11.074

[20] Friedemann, P., Olaf, H., Vadim, V.N. and Risto, J.I. (2005) Functional Links between Motor and Language Systems. European Journal of Neuroscience, 21, 793-797, http://dx.doi.org/10.1111/j.1460-9568.2005.03900.x

[21] Green, S.M. (2011) Cheerio, Laddie! Bidding Farewell to the Glasgow Coma Scale. Annals of Emergency Medicine, 58, 427-430. http://dx.doi.org/10.1016/j.annemergmed.2011.06.009

[22] Bassi, S., Buxton, N., Punt, J.A. and O’Reilly, G. (1999) Glasgow Coma Scale: A Help or a Hindrance? British Journal of Neurosurgery, 13, 526-539.

[23] Malec, J.F., Brown, A.W., Leibson, C.L., Flaada, J.T., Mandrekar, J.N., Diehl, N.N., et al. (2007) The Mayo Classification System for Traumatic Brain Injury Severity. Journal of Neurotrauma, 24, 1417-1424. http://dx.doi.org/10.1089/neu.2006.0245

[24] Balestreri, M., Czosnyka, M., Chatfield, D.A., Steiner, L.A., Schmidt, E.A., Smielewski, P., et al. (2004) Predictive Value of Glasgow Coma Scale after Brain Trauma: Change in Trend over the Past Ten Years. Journal of Neurology, Neurosurgery \& Psychiatry, 75, 161-162.

[25] Buechler, C.M., Blostein, P.A., Koestner, A., Hurt, K., Schaars, M. and McKernan, J. (1998) Variation among Trauma Centers' Calculation of Glasgow Coma Scale Score: Results of a National Survey. The Journal of Trauma, 45, 429-432. http://dx.doi.org/10.1097/00005373-199809000-00001

[26] Moskopp, D., Stähle, C. and Wassmann, H. (1995) Problems of the Glasgow Coma Scale with Early Intubated Patients. Neurosurgical Review, 18, 253-257. http://dx.doi.org/10.1007/BF00383876

[27] Mena, J.H., Sanchez, A.I., Rubiano, A.M., Peitzman, A.B., Sperry, J.L., Gutierrez, M.I. and Puyana, J.C. (2011) Effect of the Modified Glasgow Coma Scale Score Criteria for Mild Traumatic Brain Injury on Mortality Prediction: Comparing Classic and Modified Glasgow Coma Scale Score Model Scores of 13. The Journal of Trauma, 71, 1185-1193. http://dx.doi.org/10.1097/TA.0b013e31823321f8

[28] Marshall, L.F., Eisenberg, H., Marshall, S.B., Klauber, M.R. and Jane, J.A. (1991) A New Classification of Head Injury Based on Computerized Tomography. Journal of Neurosurgery, 75, S14-S20.

[29] McNarry, A.F. and Goldhill, D.R. (2004) Simple Bedside Assessment of Level of Consciousness: Comparison of Two Simple Assessment Scales with the Glasgow Coma Scale. Anaesthesia, 59, 34-37. http://dx.doi.org/10.1111/j.1365-2044.2004.03526.x

[30] Wijdicks, E.F., Bamlet, W.R., Maramattom, B.V., Manno, E.M. and McClelland, R.L. (2005) Validation of a New Coma Scale: The FOUR Score. Annals of Neurology, 58, 585-593. http://dx.doi.org/10.1002/ana.20611 